\title{
Single Fetal Death in Triplet Pregnancy
}

\author{
Akhter $\mathrm{SN}^{1}$, Sheikh $\mathrm{R}^{2}$, Russo $\mathrm{AS}^{3}$, Tasneem $\mathrm{S}^{4}$.
}

\begin{abstract}
The single fetal death in multiple pregnancy is not rare. Death of one fetus in multiple pregnancy increases the risk of mortality and morbidity of the surviving fetus. Proper diagnosis and intervention in appropriate time can improve the maternal and neonatal outcome. Adequate counselling psychological support and close follow up are mandatory.
\end{abstract}

Key words : triplet, fetal demise

\section{Introduction}

Multiple pregnancy still constitute a difficult therapeutic problem. The incidence of multiple pregnancy described as Hellin's Formula : The number of twin is $1 / n$, triplet $1 / n^{\wedge} 2$ etc. Single or more fetal demise in multiple pregnancy is not rare and it may complicate the situation. The risk of mortality and morbidity in the surviving fetuses are considerable ${ }^{1}$. The death of one fetus in multiple pregnancy is also a shock to the parents and the attending obstetrician, who need to face the substantial fetal and maternal risks.

\section{Case Report}

A 26 years old patient, gravida $3^{\text {rd }}$, para 2 of which one was perinatal death, attended OPD of ICMH at her 34 weeks of gestation as diagnosed case of twin pregnancy. She had ultrasonography at her 9 weeks, 20 weeks and 31 weeks of gestation and diagnosed as a case of twin pregnancy. She was moderately anaemic $(\mathrm{Hb} \% 47 \%)$, Blood group B+ve, Blood sugar fasting $5.4 \mathrm{mmol} / \mathrm{l}$ and 2 hours after breakfast was 6.8 $\mathrm{mmol} / \mathrm{l}$. She was normotensive $(100 / 70 \mathrm{~mm} \mathrm{Hg})$ at her 36 weeks of gestation and was treated with iron and calcium. She again attended at her 37 weeks of gestation with less fetal movement and on examination her BP was found 120/90 mm $\mathrm{Hg}$, and the attending doctor advised her to get admitted in the hospital. But the patient refused to get admitted. After one

1. Corresponding Author : Dr. Syeda Nazia Akhter, FCPS Assistant Professor (Obstatic \& Gynae) Institute of Child and Mother Health, Dhaka

2. Prof. Dr. Rumana Sheikh, FCPS, MS, Professor (Obstatic \& Gynae) Institute of Child and Mother Health, Dhaka

3. Dr. Ahmad Sharif Russo DGO Student Institute of Child and Mother Health, Dhaka

4. Sumaya Tasneem MBBS Student, Chittagong Medical College day she got admitted in ICMH and LUCS was done due to PET and less fetal movement. Two healthy babies of $2.3 \mathrm{kgs}$ and $2.4 \mathrm{kgs}$ were brought out and surprisingly another dead baby was brought out and thus it was diagnosed as a case of triplet pregnancy with one fetal demise. Placenta was single but the amniotic cavity was separate. Coagulation profile was done post operatively. All were within normal limit, but the FDP was increased $(21.67 \mu \mathrm{g} / \mathrm{dl})$. Post operatively mother and both the alive babies were in close supervision for any ominous sign. Fortunately the mother and both the babies were healthy and discharged on $5^{\text {th }}$ POD with proper counselling and advice.

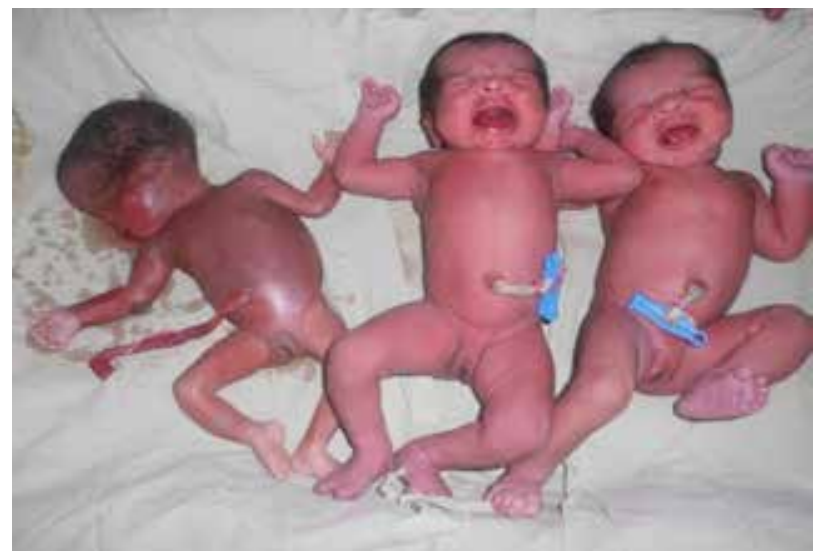

Figure: Two healthy baby with one IUD of triplet pregnancy.

\section{Discussion}

There is not much of reporting about one fetal demise in triplet pregnancy. One reporting is present that showed intrauterine death of two fetus in triplet pregnancy ${ }^{2}$. Enbon has reported the incidence of twin pregnancy with single intrauterine death ranging from $0.5 \%$ to $6.8 \%{ }^{1}$. When the fetal death occurs after midgestation there is $17 \%$ chance that the surviving fetus in monochorionic gestation will either die or suffer from major morbidity ${ }^{3}$. Major morbidity is unlikely to occur in surviving twin of a dichorionic gestation ${ }^{4}$. Intrauterine death can occur during any gestation. However a reliable estimation of the incidence with reference of the post conceptional loss is difficult as large prospective studies are scarce. Among the 7 cases studied, the gestational time varied from $19^{\text {th }}-38^{\text {th }}$ weeks ${ }^{5}$, with no apparent clustering. The timing is crucial because of its implication for remaining course of the pregnancy. Vanishing twin phenomena is relatively common and the prognosis of the surviving fetus is good ${ }^{6}$. In contrast, single fetal death in $2^{\text {nd }}$ and $3^{\text {rd }}$ trimester is uncommon and has been shown to be associated with increased risk of mortality and morbidity of surviving fetus 7-9. Chorionicity rather than zygosity determines the risk of mortality and morbidity. The prevalence of monochorionicity in single intrauterine death in twin is $50 \%$ to $70 \%{ }^{10,11}$. 
Maternal coagulopathy following multiple pregnancy demise appears to be uncommon ${ }^{12,13}$. However coagulopathy has been reported upto 3 weeks following fetal demise.

In case of multiple pregnancy, ultrasonographic evaluation is important to confirm the number of pregnancy, chorionicity and fetal well being. Triplet may be misdiagnosed as twin in ultrasonography, if not properly evaluated. Death of one fetus in late $2^{\text {nd }}$ and $3^{\text {rd }}$ trimester is associated with significant morbidity and mortality of the surviving fetus(es). Prompt delivery following death of one fetus in multiple pregnancy may save other fetuses as well as mother from getting affected.

\section{References}

1. Enbon J.A. Twin pregnancy with intrauterine death of one twin. Am J. Obstet Gynecol.1985;152:434-9

2. Teliga Czajkowska J, Dadalska E, Soplinski A. Triplet pregnancy complicated by intrauterine deaths of two fetuses-case report. Ginekol Pol.2003 Oct; 74(10):13052

3. Carlson NJ, Towers CV. Multiple gestation complicated by death of one fetus. Obstet Gynecol.1989;73:685

4. Saito K,et al. Perinatal outcome and management of single fetal death in twin pregnancy: a case series and review. J Perinat Med.1999;27:473-7

5. HHN Woo, SY Sin, LCH Tang. Single fetal death in twin pregnancy: review of maternal and neonatal outcome and management. HKMJ 2000;6:293-300
6. Landy HJ. Weiner S, Corson SL, et al. The 'vanishing twin': ultrasonograpic assesment of of foetal disappearence in the first trimester. Am J Obstet Gynecol.1986;155:424-9

7. Landy HJ, Weiner AB. Management of multiple gestation complicated by an antepartum fetal demise. Obstet Gynecol Survey.1989;44:171-6

8. Fusi L, Gordon H. Twin pregnancy complicated by single intrauterine death. Problems and outcome with conservative management. Br J Obstet Gynecol 1990;97:511-16.

9. Sonneveld SW, Correy JF. Antenatal loss of one twins. Aust NZ J Obstet Gynecol 1992;32: 1-10

10. Santema JG, Swaak AM, Wallenburg HC. Expectant management of twin pregnancy with one fetal death. $\mathrm{Br}$ J Obstet Gynecol 1995;102: 26-30.

11. Karl WM. Intrauterine death in a twin: implications for the survivor. In: Ward RH, Whittle M, editors. Multiple pregnancy. London: RCOG Press. 1995;218-30

12. Axt R Et al. maternal and neonatal outcome in twin pregnancy complicated by single fetal death. J Perinat Med. 1999;27:221-7

13. Peterson R, Nyholm HC. Multiple pregnancy with single intrauterine demise-description of 28 pregnancies. Acta Obstet Gynecol, second. 1999;78: 202-6 